\title{
Non-Cardiogenic Pulmonary Edema With Refractory Hypotension in a Child From Amlodipine Overdoses
}

\author{
Inva Gjeta ${ }^{a}$,, Durim Sala ${ }^{a}$, Ilirjana Bakallia ${ }^{a}$ Ermela Celaj ${ }^{a}$, Elmira Kola ${ }^{a}$
}

\begin{abstract}
Intoxications from calcium blockers are not common in daily pediatric practice, but often they can be life-threatening and result fatal for children. Non-cardiogenic edema in children as a result of overdose from amlodipine is rare. In this article, we want to present a case of an intentional intoxication from overdose of amlodipine in a teen girl who suffered complications with refractory hypotension and non-cardiogenic pulmonary edema after 2 days from ingestion. This article wants to highlight the reporting of this rare life-threatening complication because of overdose. It will also focus on the successful supportive treatment with liquids, salt of calcium, vasopressors, glucagon, intra-lipids, mechanical ventilation and the superiority of using highdose insulin-euglycemia in the concomitant refractory hypotension.
\end{abstract}

Keywords: Amlodipine; Non-cardiogenic pulmonary edema; Highdose insulin-euglycemia; Refractory hypotension

\section{Introduction}

Intoxications are one of the most difficult diagnoses and present therapeutic challenges, especially in children. According to the 2018 Annual Report of the American Association of Poison Control Center, about 1.2 million children are exposed to intoxications every year. Intoxications from calcium blockers are included in the list of 25 substances most exposed and are ranked the sixth for the number of fatalities over the total number of exposures.

Amlodipine is part of the dihydropyridines class and has a half-plasmatic life of $30-50 \mathrm{~h}$, with a plasmatic peak of $6-12$ $\mathrm{h}$ and a volume of distribution $21 \mathrm{~L} / \mathrm{kg}$ weight [1-5]. Clinical manifestations of intoxications from calcium blockers have a

Manuscript submitted July 28, 2020, accepted August 14, 2020

Published online September 2, 2020

aPediatric Intensive Care Unit, University Hospital Center "Mother Theresa", Tirana, Albania

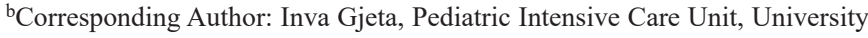
Hospital Center "Mother Theresa", Tirana, Albania.

Email: invagjeta@hotmail.com

doi: https://doi.org/10.14740/ijcp398 large specter of signs and symptoms from the asymptomatic in the first hours from ingestion to dizziness, vomiting, confusion, bradycardia or tachycardia, atrioventricular block, legs edema, constipation, cardiogenic and non-cardiogenic pulmonary edema, severe hypotension and shock.

The class of dihydropyridines, in which amlodipine is included, prefers vascular muscle cell causing vasodilatation and hypotension as consequence. In toxic doses, it causes bradycardia and cardiogenic shock.

This is the case of a teen girl overdosing from amlodipine, complicated with non-cardiogenic pulmonary edema and concomitant refractory hypotension. The phenomenon is rare in literature, especially in children, and the treatment is a challenge for medical personnel. In our case the treatment was supportive and was based on hemodynamic and respiratory assistance. After the use of high dose of insulin-euglycemia a significant improvement of hemodynamic parameters were noticed.

\section{Case Report}

A 13-years old Caucasian female with body weight $60 \mathrm{~kg}$ was hospitalized in the Pediatric Emergency Service $7 \mathrm{~h}$ after ingesting 20 tablets of $5 \mathrm{mg}$ amlodipine. During that time, the girl was living with her parents and grandparents and had two older brothers. After an argument with her mother, the girl took the tablets intentionally. The tablets that were used for treatment of hypertension belonged to her grandfather. The girl was not receiving any other treatment, and this was the first incident in her medical history.

During admission, she was conscious, alert, reported adequately and complained about fatigue and nausea. The pupils' sizes were isochoric and reacted to light, without nystagmus, without nuchal rigidity and with signs of motor and sensory deficiency. Glasgow coma scale score was $15 / 15$ and there was no trauma on inspection.

Auscultation of cardiac tones was regular, without murmur or gallop with 109 beats per min (bpm). Arterial tension was $115 / 70 \mathrm{~mm} \mathrm{Hg}$, the pulse was good on radial palpation on 109 bpm, body temperature was $36.9^{\circ} \mathrm{C}$, respiratory rate was 20 breaths $/ \mathrm{min}$ and oxygen saturation were $95 \%$ on air room. In the lungs, auscultation is clear, without rhonchi, vesicular respiration without polypnea or dyspnea. Medical record did not refer the use of other drugs, substances or the use of alcohol.

Lab tests of complete blood revealed that red blood cell 


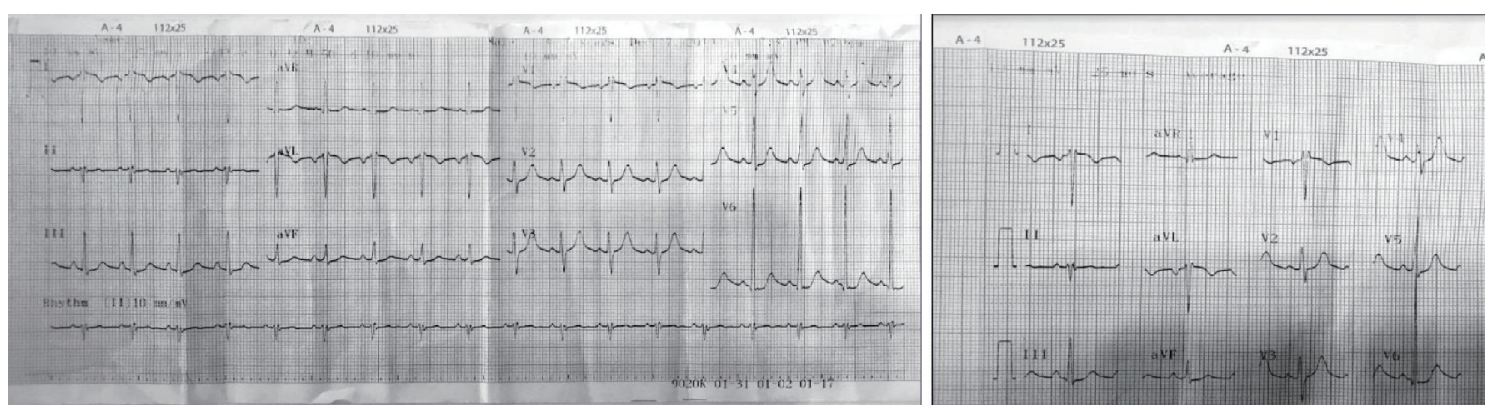

Figure 1. ECG on admission. ECG: electrocardiogram.

(RBC) $4.37 \times 10^{6} / \mathrm{mm}^{3}$ (range: $4.2-6.1 \times 10^{6} / \mathrm{mm}^{3}$ ); white blood cell (WBC) $12.1 \times 10^{3} / \mathrm{mm}^{3}$ (range: $4-12 \times 10^{3} / \mathrm{mm}^{3}$ ), leukocyte formula with granulocytes $75.5 \%$ (range: $43-76 \%$ ), lymphocytes $21 \%$ (range: $17-48 \%$ ) and monocytes $3.5 \%$; hemoglobin (Hb) level $11.8 \mathrm{~g} / \mathrm{dL}$ (range: 11 - $16 \mathrm{~g} / \mathrm{dL}$ ); PLT 248 $\times 10^{3} / \mathrm{mm}^{3}$ (range: $150-390 \times 10^{3} / \mathrm{mm}^{3}$ ).

Biochemical testes were on normal range: glycemia $96 \mathrm{mg} /$ dL (range: 70 - $106 \mathrm{mg} / \mathrm{dL}$ ) ; urea nitrogen $40 \mathrm{mg} / \mathrm{dL}$ (range: 10 - $43 \mathrm{mg} / \mathrm{dL}$ ); creatinine $1 \mathrm{mg} / \mathrm{dL}$ (range: 0.6 - $1.2 \mathrm{mg} / \mathrm{dL}$ ); aspartate aminotransferase (AST) $27 \mathrm{U} / \mathrm{L}$ (range: 0 - $35 \mathrm{U} / \mathrm{L}$ ); alanine transaminase (ALT) $23 \mathrm{U} / \mathrm{L}$ (range: 0 - $45 \mathrm{U} / \mathrm{L}$ ); lactate dehydrogenase (LDH) $266 \mathrm{U} / \mathrm{L}$ (range: 125 - $250 \mathrm{U} / \mathrm{L}$ ); creatine kinase $160 \mathrm{U} / \mathrm{L}$ (range: 0 - $170 \mathrm{U} / \mathrm{L}$ ) total bilirubin $0.4 \mathrm{mg} / \mathrm{dL}$ (range: 0.3 - $1.2 \mathrm{mg} / \mathrm{dL})$; total protein $7 \mathrm{~g} / \mathrm{dL}(6-8.3 \mathrm{~g} / \mathrm{dL}) ; \mathrm{Na} 136 \mathrm{mEq} / \mathrm{L}$ (135 - $145 \mathrm{mEq} / \mathrm{L}$ ); K $4.1 \mathrm{mEq} / \mathrm{L}$ (range: 3.5 - $5.1 \mathrm{mEq} / \mathrm{L}$ ); total calcium $8.8 \mathrm{mg} / \mathrm{dL}$ ( normal range: $8-10.2 \mathrm{mg} / \mathrm{dL}$ ); $\mathrm{Ca}^{2+} 1.22$ $\mathrm{mmol} / \mathrm{L}$ (range: 1.1 - $1.3 \mathrm{mmol} / \mathrm{L}$ ); urine analysis with five leukocytes per high power field, negative for erythrocytes, ketones, glucose, protein; and with no signs of drugs found.

Blood gas analysis was normal on admission with $\mathrm{pH}$ 7.37; $\mathrm{PCO}_{2} 37.8 \mathrm{~mm} \mathrm{Hg}$; prothrombin time was $75.9 \%$ (normal range: $70-120 \%$ ), international normalized ratio (INR) 1.1 (normal range: 0.7 - 1.2); X-ray of the chest of the first day was normal, without pathologic changes. electrocardiogram (ECG) to the bed side of the patient showed a sinus tachycardiac rhythm of $110 \mathrm{bpm}$, a normal duration of interval QRS with $90 \mathrm{~ms}$ and incomplete right bundle branch block (Fig. 1).

The treatment started with $0.9 \%$ saline solution and 5\% dextrose on ratio 1:1 with intravenous (IV) infusion rate of $85 \mathrm{~mL} / \mathrm{h}$ for $24 \mathrm{~h}$ to maintain the arterial tension on normal values. After $20 \mathrm{~h}$ from admission and $27 \mathrm{~h}$ from ingestion of tablets the conditions of the patient deteriorated with severe cough, dyspnea, polypnea, need for oxygen therapy and as a result the patient was transferred to the intensive care unit.

On objective examination the skin was pale, capillary refill time more than $4 \mathrm{~s}$, the radial pulse was mild, cardiac tones without murmur, tachycardia with frequency $120 \mathrm{bpm}$, arterial tension was low with value of $100 / 65 \mathrm{~mm} \mathrm{Hg}$, in lungs auscultation crepitant rhonchus on bilateral fields was heard and on lower right lobe the respiration was reduced.

Treatment started with high-flow oxygen therapy, 10\% gluconate calcium as IV bolus with a dose $30 \mathrm{~mL}$ over $15 \mathrm{~min}$ and was repeated three times for $24 \mathrm{~h}$. Prednisolone IV use with $2 \mathrm{mg} / \mathrm{kg}$ /day for 10 days; furosemide $40 \mathrm{mg}$ IV use applied once; omeprazole $40 \mathrm{mg}$ /day IV use for 10 days; antibi- otic therapy (ceftriaxone $1.5 \mathrm{~g}$ every $12 \mathrm{~h} \mathrm{IV}$ for 14 days, and vancomycin IV use $1 \mathrm{~g}$ every $6 \mathrm{~h}$ for 10 days); dopamine IV infusion with dose $7 \mu \mathrm{g} / \mathrm{kg} / \mathrm{min}$; and norepinephrine IV infusion with $0.5 \mu \mathrm{g} / \mathrm{kg} / \mathrm{min}$ for 3 days.

Despite the treatment with high-flow oxygen therapy, the dyspnea and polypnea increased, the condition did not improve. Arterial tension decreased further in value of $70 / 40 \mathrm{~mm}$ $\mathrm{Hg}$ although the treatment with $0.9 \%$ saline solution bolus IV of $500 \mathrm{~mL}$ for $30 \mathrm{~min}$. Second bolus with same dose and the continues infusion IV of liquids of $0.9 \%$ saline solution and $5 \%$ dextrose on ratio 1:1 with rate of infusion increased with $120 \mathrm{~mL} / \mathrm{h}$ for the next $12 \mathrm{~h}$. The $10 \%$ calcium gluconate IV bolus of $30 \mathrm{~mL}$ over $15 \mathrm{~min}$ was repeated three time during subsequent $24 \mathrm{~h}$. Vasopressors dopamine was increased by 10 $\mu \mathrm{g} / \mathrm{kg} / \mathrm{min} I V$ infusion and intra-lipid $20 \%$ with $1,000 \mathrm{~mL}$ for $7 \mathrm{~h}$ IV infusion was started.

The blood gas analysis results were: $\mathrm{PCO}_{2}=33.6 \mathrm{~mm} \mathrm{Hg}$, $\mathrm{PaO} 2=41.7 \mathrm{~mm} \mathrm{Hg}, \mathrm{pH}=7.53$ and a level of lactates 3.5 $\mathrm{mmol} / \mathrm{L}$ and the level of $\mathrm{Ca}^{2+} 0.84 \mathrm{mmol} / \mathrm{L}$. These conditions lead to patient intubation with midazolam sedation and during the procedure rose foamy secretions were noted.

The chest X-ray showed bilateral diffuse opacities and pleural effusion on the right lower lobe (Fig. 2) that was confirmed with portable bedside thoracic echography. In cardiac echography, the function of left and right ventricle was normal, the size was normal and pericardia effusion was not noticed. Level of C-reactive protein was high with value of $120 \mathrm{mg} / \mathrm{L}$ (normal range: $1-8 \mathrm{mg} / \mathrm{L}$ ) $72 \mathrm{~h}$ after the admission and the

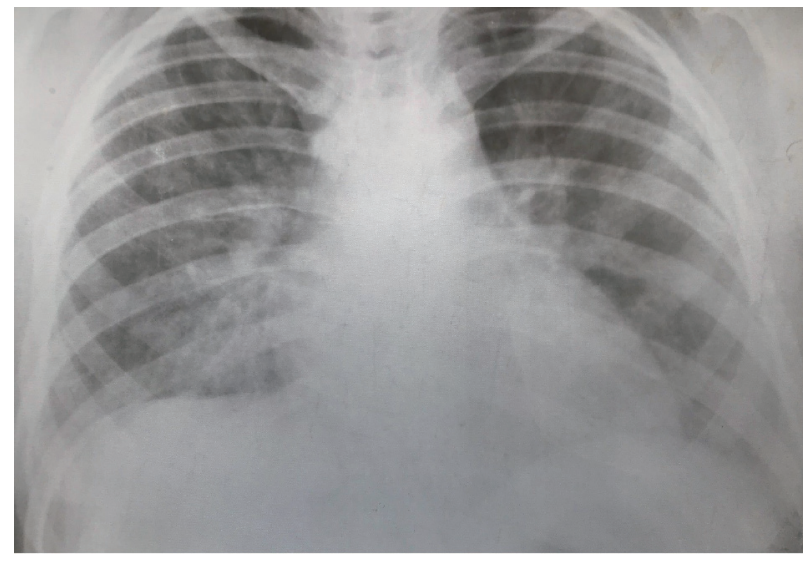

Figure 2. The chest X-ray. 


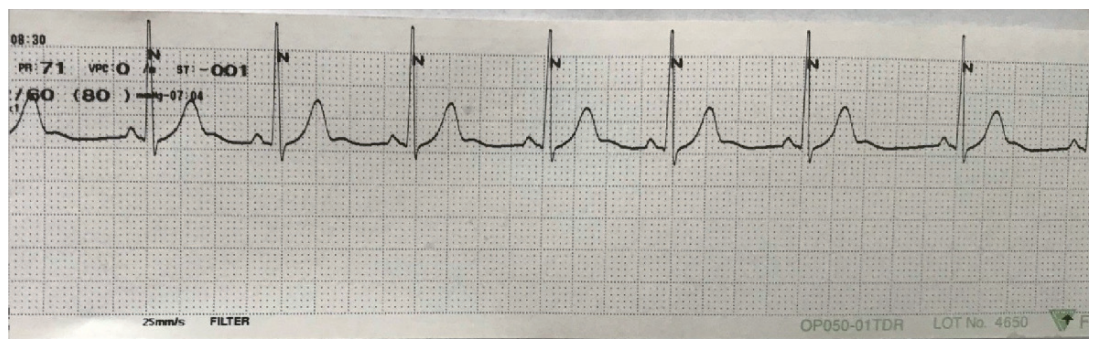

Figure 3. ECG on discharge (lead: II). ECG: electrocardiogram.

treatment with antibiotic was continued. Blood culture showed no pathogen. The culture of tracheobronchial secretions from endotracheal tube has not identified microbial growth.

Diagnosis of pediatric acute respiratory distress syndrome (PARDS) as consequence of non- cardiogenic pulmonary edema was made of severe respiratory insufficiency with hypoxemia $\left(\mathrm{PaO}_{2} / \mathrm{FiO}_{2}=102\right)$ and diffuse bilateral opacities on chest $\mathrm{X}$-ray. The refractory hypotension was persistent although the treatment with liquids, calcium, vasopressors infusion and intralipid.

The infusion of high-dose insulin-euglycemia with $0.5 \mathrm{UI} /$ $\mathrm{kg} /$ body weight was started with monitoring glycemia every 1 $\mathrm{h}$ and level of potassium every $4 \mathrm{~h}$ for the first $24 \mathrm{~h}$. Glucagon $5 \mathrm{mg}$ as IV bolus was applied only once.

During the treatment with high-dose insulin the maintenance with liquid was done with $5 \%$ dextrose and $0.9 \%$ saline solution on ratio $2: 1$ with IV infusion rate of $120 \mathrm{~mL} / \mathrm{h}$ for the subsequent $24 \mathrm{~h}$ and we give bolus of $10 \%$ dextrose on central line IV when glycemia is under $100 \mathrm{mg} / \mathrm{dL}$.

After $6 \mathrm{~h}$ of application of high doses insulin-euglycemia, the arterial tension was increased and after $24 \mathrm{~h}$ it remained on constant value of normal range. The peripheral perfusion was improved and capillary refill time was $<2 \mathrm{~s}$.

After $48 \mathrm{~h}$ therapy with high-dose insulin-euglycemia was stopped; at the same time we started the titration of vasopressors infusion and rate infusion of IV of liquid was reduced.

The patient stayed 6 days on mechanical ventilation and a total of 14 days recovered in the hospital. ECG on discharge showed normal sinus rhythm without pathologic change (Fig. $3)$.

The case was referred to pediatric psychiatrist before the discharge. We made two routine visits during 7 months from her discharge and the girl was in good condition. The psychiatrist recommended a follow-up for 1 year every 3 months.

\section{Discussion}

We described a case of a teen girl with intentional overdose of amlodipine that was complicated with non-cardiogenic pulmonary edema. She developed a hypotension that was refractory from the treatment with liquids, vasopressors and responded well after the start of the therapy with high-dose insulin-euglycemia.

During the review of literature for intoxications from amlodipine the presence of the non-cardiogenic pulmonary edema was rare and in children there are fewer cases. Our case demonstrates this complication at a small age of 13 years old. The treatment for intoxication from amlodipine (calcium channel blocker) consists of support therapy. In some cases, use of high-dose insulin-euglycemia has more benefits on the treatment of the concomitant hypotension.

Calcium blockers are divided in three main chemical classes where each of them present different affinity for cardiac tissue and blood vessels [6]: 1) Phenylalkylamine class (verapamil); 2) Benzothiazepine class (diltiazem); and 3) Dihydropyridines where it is included amlodipine, nicardipine, nifedipine, etc.

The first class has strong affinity for myocardia and blood vessels reducing the conduction on atrioventricular node, has negative inotropic effect and causes moderated vasodilatation [7]. The second class has more negative chronotropic effect and less vasodilatation. The third class, including amlodipine, causes more vasodilatation and has less negative inotropic and chronotropic effect in myocardia [1, 5, 7-9]. Calcium blockers have a narrow therapeutic index; and overdoses from this have a large variety of signs and complains. Hypotension is a consequence of some mechanisms such as negative inotropic and chronotropic effect in myocardia and peripheral vasodilation $[10,11]$.

Amlodipine is a long-acting calcium blocker that is bound with around $90 \%$ with proteins and in cases of overdoses it can cause hypotension, dysrhythmia and vasodilatory shock [12]. Amlodipine has selectivity for inhibition of L-type calcium channel on vascular smooth muscle cell and in cases of overdose this selectivity fails and can give myocardial depression closing the channels on cardiac tissue [4]. Toxicity from amlodipine is manifest with 5 - 10 folds of therapeutic doses.

A rare complication of overdoses from amlodipine is noncardiogenic pulmonary edema. In the case of our patient, this complication was noted on the second day of ingestion and along with refractory hypotension from liquids and vasopressors. Reporting of this phenomenon is not common, particularly for children. One case of 14 years old and the other 18 years old with non-cardiogenic pulmonary edema and one child of 11 months with refractory shock as consequence of overdoses from amlodipine were reported $[1,13,14]$. The mechanism of non-cardiogenic pulmonary edema is not clear, but it is thought as a consequence of precapillary selective vasodilatation that causes an elevation of hydrostatic pressure that gives an interstitial edema [2,11, 13, 15-17].

One factor that contributes in non-cardiogenic pulmonary edema is thought to be the overload volume in the initial phase of resuscitation $[15,18-20]$. Treatment is supportive; gastric 
decontamination if the patient is present within $1-2 \mathrm{~h}$ from ingestion; active carbon is preferred to use within the first hour but can be used within $24 \mathrm{~h}$ from ingestion; liquids; calcium salts; atropine; vasopressors; glucagon and intralipid [21].

In the case of our patient, it was noted a refractory hypotension, despite treatments with liquids, calcium bolus, vasopressors (dopamine and norepinephrine,) glucagon bolus and intralipid. After the treatment of high-dose insulin-euglycemia arterial tension was increased and remained in constant normal values, cardiac rhythm was on normal range, peripheral perfusion was improved (capillary refill time $<2 \mathrm{~s}$ ) and with a decrease of lactate levels.

In cases of severe intoxications from calcium blockers when the patients are refractory from supportive therapy (liquids, calcium and vasopressors), the high-dose insulin-euglycemia should be selected as specific therapy $[15,20,22,23]$.

There are not randomized control trial in humans to compare the use of vasopressors and high-dose insulin-euglycemia, but the study in animals and cases study in humans indicate a superiority of high-dose insulin-euglycemia in improvement of hemodynamic parameters in severe intoxications from calcium blockers [7, 11, 13, 15, 20, 24-27]. The mechanism of action of insulin is thought to be the trigger uptake of glucose from myocardia improving contractility effect of it [20, 25-29]. PARDS as noted in our patient, is related with non-cardiogenic pulmonary edema that was treated with mechanical ventilation and cortico-therapy.

In our case, it should be mentioned that this complication from amlodipine overdoses was presented for the first time. The supportive therapy includes many treatment lines, making it difficult narrow the precise interpretation of the superiority of each. The patient recovered successfully, and we noticed that after many hours of treatment with high-dose insulin-euglycemia the improvement of hemodynamic parameters was evident.

\section{Conclusions}

Reporting of rare cases of non-cardiogenic pulmonary edema from amlodipine overdoses especially in children contributes to a good knowledge and early treatment of complications that may be life-threatening. The treatment of intoxications from calcium blockers is supportive and multifactorial with liquids, calcium, atropine, vasopressors, glucagon, high-dose insulin-euglycemia, intra-lipid, and extracorporeal membrane oxygenation (ECMO). In cases of refractory hypotension, consideration should be given to treatments with high-dose insulin-euglycemia.

\section{Acknowledgments}

None to declare

\section{Financial Disclosure}

No funding was received. None of the authors has disclosures relevant to this manuscript.

\section{Conflict of Interest}

None to declare.

\section{Informed Consent}

Not applicable.

\section{Author Contributions}

All authors contributed to editing of the manuscript. Inva Gjeta wrote the manuscript and made the accompanying figures.

\section{Data Availability}

The authors declare that data supporting the findings of this study are available within the article.

\section{References}

1. Ramos M, Graciano P, Cabrera D, Mota C, Corona L. Intoxication with amlodipine with hypotension and noncardiogenic edema. Cienca y Salud. 2018. Vol II. ISSN: 2613-8816.

2. Stanek EJ, Nelson CE, DeNofrio D. Amlodipine overdose. Ann Pharmacother. 1997;31(7-8):853-856.

3. Hedaiaty M, Eizadi-Mood N, Sabzghabaee AM. Noncardiogenic pulmonary edema after amlodipine overdose without refractory hypotension and bradycardia. Case Rep Emerg Med. 2015;2015:546012.

4. DeWitt CR, Waksman JC. Pharmacology, pathophysiology and management of calcium channel blocker and beta-blocker toxicity. Toxicol Rev. 2004;23(4):223-238.

5. Ramoska EA, Spiller HA, Winter M, Borys D. A one-year evaluation of calcium channel blocker overdoses: toxicity and treatment. Ann Emerg Med. 1993;22(2):196-200.

6. Pinto VL, Wenderfer SE, Morris J, Akcan-Arikan A. Treatment of Severe Amlodipine Toxicity With Molecular Adsorbent Recirculating System. Kidney Int Rep. 2019;4(2):346-349.

7. Chakraborty RK, Hamilton RJ. Calcium channel blocker toxicity. In: StatPearls. Treasure Island (FL), 2020.

8. Ramoska EA, Spiller HA, Myers A. Calcium channel blocker toxicity. Ann Emerg Med. 1990;19(6):649-653.

9. Kline JA, Raymond RM, Schroeder JD, Watts JA. The diabetogenic effects of acute verapamil poisoning. Toxicol Appl Pharmacol. 1997;145(2):357-362.

10. Kapelios CJ, Karamanakos G, Liatis S, Sarafadi M, Polizois M, Papoutsis I, Kokkinos AD. Recurrent episodes of life-threatening vasodilatory shock following unintentional intoxication with amlodipine. Hellenic J Cardiol. 2017;58(5):369-371.

11. Graudins A, Lee HM, Druda D. Calcium channel antagonist and beta-blocker overdose: antidotes and adjunct 
therapies. Br J Clin Pharmacol. 2016;81(3):453-461.

12. Benson BE, Spyker DA, Troutman WG, Watson WA, Bakhireva LN. Amlodipine toxicity in children less than 6 years of age: a dose-response analysis using national poison data system data. J Emerg Med. 2010;39(2):186193.

13. Nimbalkar SM, Patel DV. Near fatal case of amlodipine poisoning in an infant. Indian J Pediatr. 2013;80(6):513515.

14. Naha K, Suryanarayana J, Aziz RA, Shastry BA. Amlodipine poisoning revisited: Acidosis, acute kidney injury and acute respiratory distress syndrome. Indian J Crit Care Med. 2014;18(7):467-469.

15. Rietjens SJ, de Lange DW, Donker DW, Meulenbelt J. Practical recommendations for calcium channel antagonist poisoning. Neth J Med. 2016;74(2):60-67.

16. Hirachan A, Baral S, Shareef M, Rijal R, Laxman T. Amlodipine overdose with hypotension and noncardiogenic pulmonary edema. Nepalese Heart Journal. 2016;13(1):27-29.

17. Humbert VH, Jr., Munn NJ, Hawkins RF. Noncardiogenic pulmonary edema complicating massive diltiazem overdose. Chest. 1991;99(1):258-259.

18. Shetty K, Sherif L, Babu R, Bhatt G. Noninvasive ventilation in a patient with noncardiogenic pulmonary edema following amlodipine poisoning. J Anaesthesiol Clin Pharmacol. 2015;31(2):264-266.

19. Siddiqi TA, Hill J, Huckleberry Y, Parthasarathy S. Noncardiogenic pulmonary edema and life-threatening shock due to calcium channel blocker overdose: a case report and clinical review. Respir Care. 2014;59(2):e15-21.

20. De Ros F. Calcium channel blockers. In: Hoffman R, ed. Goldfrank's toxicologic emergencies.10th ed. New York: McGraw-Hill; 2015:884-892.
21. Calcium channel blocker poisoning. Available at: https:// www.uptodate.com/contents/search.

22. Shah SK, Goswami SK, Babu RV, Sharma G, Duarte AG. Management of calcium channel antagonist overdose with hyperinsulinemia-euglycemia therapy: case series and review of the literature. Case Rep Crit Care. 2012;2012:927040.

23. Selej M, Farber M. Non cardiogenic pulmonary edema in amlodipine overdose. Chest. 2011;140:130A.

24. Patel NP, Pugh ME, Goldberg S, Eiger G. Hyperinsulinemic euglycemia therapy for verapamil poisoning: a review. Am J Crit Care. 2007;16(5):498-503.

25. Nickson CP, Little M. Early use of high-dose insulin euglycaemic therapy for verapamil toxicity. Med J Aust. 2009;191(6):350-352.

26. Cole JB, Arens AM, Laes JR, Klein LR, Bangh SA, Olives TD. High dose insulin for beta-blocker and calcium channel-blocker poisoning. Am J Emerg Med. 2018;36(10):1817-1824.

27. Seegobin K, Maharaj S, Deosaran A, Reddy P. Severe beta blocker and calcium channel blocker overdose: Role of high dose insulin. Am J Emerg Med. 2018;36(4):736 e735-736 e736.

28. Singh B, Sangle GV, Murugan J, Umrani R, Roy S, Kulkarni O, Semwal A, et al. Effect of combination treatment of S-amlodipine with peroxisome proliferator-activated receptor agonists on metabolic and cardiovascular parameters in Zucker fa/fa rats. Diabetol Metab Syndr. 2014;6(1):45.

29. Kute VB, Shah PR, Goplani KR, Gumber MR, Vanikar $\mathrm{AV}$, Trivedi HL. Successful treatment of refractory hypotension, noncardiogenic pulmonary edema and acute kidney injury after an overdose of amlodipine. Indian J Crit Care Med. 2011;15(3):182-184. 